\title{
Efficacy of Pleuran ( $\beta$-Glucan from Pleurotus ostreatus) in the Management of Herpes Simplex Virus Type 1 Infection
}

\author{
Ingrid Urbancikova, ${ }^{1,2}$ Dana Hudackova, ${ }^{2}$ Juraj Majtan $\mathbb{D}^{3},{ }^{3}$ Zuzana Rennerova $\mathbb{D}^{4,5}$ \\ Peter Banovcin, ${ }^{6}$ and Milos Jesenak ${ }^{60,7,8}$ \\ ${ }^{1}$ Department of Pediatrics, P. J. Safarik University, Faculty of Medicine, Children Faculty Hospital, Trieda SNP 1, \\ 04011 Kosice, Slovakia \\ ${ }^{2}$ Department of Pediatric Infectology, Children Faculty Hospital, Faculty of Medicine, Trieda SNP 1, 04011 Kosice, Slovakia \\ ${ }^{3}$ Institute of Molecular Biology, Slovak Academy of Sciences, Dubravska Cesta 21, 84551 Bratislava, Slovakia \\ ${ }^{4}$ Pneumo-Allergo Centre Ltd., Udernicka 1, 85101 Bratislava, Slovakia \\ ${ }^{5}$ Department of Pediatric Pulmonology and Phthisiology, Faculty of Medicine, Slovak Medical University, \\ National Institute of Children Diseases, Krajinska 91, 82556 Bratislava, Slovakia \\ ${ }^{6}$ Department of Paediatrics, Jessenius Faculty of Medicine, Comenius University in Bratislava, Kollarova 2, \\ 03659 Martin, Slovakia \\ ${ }^{7}$ Department of Pulmonology and Phthisiology, Jessenius Faculty of Medicine, Comenius University in Bratislava, Kollarova 2, \\ 03659 Martin, Slovakia \\ ${ }^{8}$ Department of Clinical Immunology and Allergology, Comenius University in Bratislava, Kollarova 2, 03659 Martin, Slovakia
}

Correspondence should be addressed to Zuzana Rennerova; zuzana.rennerova@yahoo.com and Milos Jesenak; jesenak@gmail.com

Received 31 December 2019; Accepted 24 March 2020; Published 13 April 2020

Academic Editor: Letizia Angiolella

Copyright ( $\odot 2020$ Ingrid Urbancikova et al. This is an open access article distributed under the Creative Commons Attribution License, which permits unrestricted use, distribution, and reproduction in any medium, provided the original work is properly cited.

\begin{abstract}
One of the highly prevalent viral pathogens among children and adults causing infection, clinically presenting as herpes labialis, is herpes simplex virus type 1 (HSV-1). The long-term administration of acyclovir, a standard regimen for therapy against HSV-1 infections, can cause viral resistance against this drug. Therefore, the development of natural drugs with low toxicity that are able to enhance host antiviral defense against HSV infection is needed. $\beta$-Glucans represent a type of biologically active molecules possessing antiviral properties. The goal of this study was to investigate the clinical and immunomodulatory effect of $\beta$-glucan pleuran (insoluble $\beta$-1,3/1,6-D-glucan isolated from Pleurotus ostreatus) based supplements on the duration and intensity of herpes symptoms and on the incidence rate and duration of acute respiratory symptoms and intercurrent diseases in HSV-1 positive patients. Ninety patients were randomised into active and placebo groups. Active treatment with pleuran in systemic application caused a significantly shorter duration of herpes simplex symptoms compared to the placebo group. During the preventive phase (120 days), the duration and severity of respiratory symptoms were lower in the active group compared to the placebo group; however, a significant difference was found only in the case of cough. No significant side effects were observed during both phases of the clinical trial (acute and preventive). Obtained results suggest that the use of pleuran seems to be a promising approach in the treatment of acute HSV-1 with beneficial effect on the respiratory tract symptoms and infections.
\end{abstract}

\section{Introduction}

$\beta$-Glucans are glucose polymers derived from a variety of sources, including yeast, grain, alga, and fungus, and belong to the class of drugs known as biological response modifiers
[1]. Nowadays, $\beta$-glucans have attracted considerable attention due to their anti-infective, antiviral, antitumor, and immunomodulatory activities as well as wound healing properties [2-7]. As for their antiviral effect, $\beta$-glucans have shown excellent activity against a broad spectrum of plant, 
animal, and human viruses, such as the infectious haematopoietic necrosis virus [8], spring viremia of carp virus [9], dengue virus [10], herpes simplex virus type 1 (HSV-1) [11], human immunodeficiency virus 1 [12], influenza virus $[13,14]$, and tobacco mosaic virus [15]. Despite in vitro and in vivo evidence of the antiviral effect of $\beta$-glucans, to date, only a few human and animal clinical studies have been conducted utilizing $\beta$-glucans in treatment or prevention of viral infections [16-20].

The antiviral effect of $\beta$-glucans can be mediated directly through the inhibition and/or disruption of virus particles or indirectly by enhancing host antiviral defense. The mechanism of $\beta$-glucan's action is mediated through several receptors, especially the dectin-1 receptor, toll-like receptors (TLR 2, 4, and 6), complement receptor 3 (CR3), scavenger receptor, and lactosylceramide [21]. The most important is the dectin-1 receptor, which is highly expressed in many immunocompetent cells, such as dendritic cells (DC), neutrophils, eosinophils, macrophages, monocytes, and several T lymphocytes [22, 23].

One of the highly prevalent viral pathogens among children and adults causing infection, clinically presenting as herpes labialis, is herpes simplex virus type 1 (HSV-1). Acyclovir, a nucleoside analogue, has been used as a standard regimen for the control of HSV-1 by interfering with viral DNA synthesis. However, the prolonged use of acyclovir, in particular in immunocompromised patients, has led to viral resistance against this drug. Acyclovir-resistant HSV strains have been isolated in $5-10 \%$ of patients and are associated with significant morbidity [24]. Furthermore, acyclovir has low bioavailability and possesses a wide array of side effects, which can limit its short- and long-term use in children. Therefore, current research is focused on the development of natural drugs that are able to enhance host antiviral defense against HSV-1 infection.

Fungal and oat $\beta$-glucans exhibit in vitro antiherpetic activity and inhibit viral adsorption, penetration, and cellto-cell spread $[11,25,26]$ and increase the macrophage proinflammatory cytokine response to HSV-1 infection [27]. Therefore, they may represent potential prophylactic/ treatment agents in HSV-1 infection and can decrease susceptibility to viral infection following oral administration of $\beta$-glucans.

The aim of the present study was to investigate the clinical and immunomodulatory effect of $\beta$-glucan pleuran (insoluble $\beta$-1,3/1,6-D-glucan isolated from Pleurotus ostreatus) based supplements on the duration and intensity of herpes symptoms (10-day acute treatment phase of HSV-1 infection) and on the incidence rate and duration of acute respiratory symptoms and intercurrent diseases in HSV-1 positive patients (120-day preventive phase).

\section{Materials and Methods}

2.1. Subjects. A multicentre, randomised, double-blind, placebo-controlled study was conducted by the Department of Infectious Diseases, Children Faculty Hospital in Kosice and 6 outpatient paediatric clinics across Slovakia between November 2014 and December 2017.
The study population included 90 patients aged over 6 years with herpes simplex facialis/labialis in one of the first three stages (prodromal/tingle stage, blister stage, or weeping stage) at the time of the screening visit.

Subjects with a history of severe primary or secondary immunodeficiency, invasive bacterial infection (e.g., sepsis and meningitis) in the prior 14 days and product allergies or intolerance as well as those who had used some systemic antiviral treatment (acyclovir, valacyclovir, or famciclovir) or any immunomodulatory therapy (bacterial lysates, $\beta$-glucans, probiotics, prebiotics, Echinacea, enzyme therapy, inosine pranobex, azoximer bromide, etc.) in the prior 28 days or those who were pregnant, breastfeeding, and unable to complete diary cards were excluded from the study.

The patients or their parents/tutors were informed about the conduction of the study, and their written informed consent was obtained.

2.2. Study Design. The study consisted of the following 2 phases: acute treatment phase (the first 10 days) and preventive phase (120 days after herpes lesion treatment). Subjects that met all the inclusion criteria were randomised into two different treatment groups to receive either $\beta$-glucan-based supplement or placebo. During the acute treatment phase, subjects in the active group $(n=49)$ were given 1 capsule of combined supplement containing pleuran $300 \mathrm{mg}$, vitamin C $160 \mathrm{mg}$, and zinc $10 \mathrm{mg}$ (Imunoglukan P4H ${ }^{\circledR}$ ACUTE!) every morning on an empty stomach for 10 days as well as the recommended antiherpetic treatment (topical antiviral agents, analgesics, wound healing creams, or herpes patches). The placebo group $(n=41)$ followed the same treatment schedule including antiherpetic products but was given 1 capsule containing only $160 \mathrm{mg}$ of vitamin C and $10 \mathrm{mg}$ of zinc. Randomization was performed at the beginning of the study, and the unblinding was done after the completion of all the data. Active treatment and placebo did not differ in the shape, colour, taste, or smell.

A total of 77 out of 90 patients were followed up during the subsequent 120-day preventive phase. Subjects from the active and placebo groups were required to take 1 capsule of combined supplement containing $100 \mathrm{mg}$ of pleuran and $100 \mathrm{mg}$ of vitamin $\mathrm{C}$ (Imunoglukan $\mathrm{P} \mathrm{H}^{\circledR}$ ) and placebo (100 mg of vitamin C), respectively, every morning on an empty stomach.

The active substance of the administered natural products was isolated by unique and patented technology from Pleurotus ostreatus. It was previously identified and chemically characterized by Karacsonyi and Kuniak [28].

The study protocol followed the guidelines of the Declaration of Helsinki and was approved by the Ethics Committees of the Children's Faculty Hospital in Kosice and of the Kosice Self-Governing Region.

Patients underwent five clinical visits during the whole study period: V0 (day 0) - screening visit on recruitment, V1 (day 10) - after 10 days of acute treatment, V2 (day 40)after 30 days of preventive treatment, V3 (day 70)-after 60 days of preventive treatment, and V4 (day 130-the end of the 
study) - after 120 days of preventive treatment. At the time of inclusion, the anthropometric data and data on herpes occurrences in the last 6 and 12 months before enrolment as well as data on the stage, location, size of herpes efflorescence, and therapy applied were documented in all subjects.

During the acute treatment phase, study subjects maintained daily diary cards on which they noted the appearance, duration, and intensity of herpes symptoms (itching, redness, swelling, pain, exudation, scab, haemorrhage, and negative impact on daily activities) on a visual analogue scale from 0 (no symptoms) to 10 (the highest intensity). On days 0,5 , and 10 , they measured the size of herpes efflorescence. At the end of the acute treatment phase, the opinions of patients or their parents/tutors about the treatment effect ( 0 - no effect; 1-good; 2-very good) were recorded by a physician.

During the 120-day preventive phase, the following data were evaluated based on the diary cards of patients: the incidence of acute respiratory symptoms (rhinitis, cough, sore throat, earache, and fever) and intercurrent diseases (abdominal pain, aphthous stomatitis, labial herpes, shingles, skin rash, and mycotic infections), their intensity on scale 0 (no symptoms) to 3 (the highest intensity) and their duration (in days), and use of antibiotics and other concomitant therapy.

During the whole study, the tolerability of the studied products and the incidence of adverse events were also recorded.

2.3. Statistical Analysis. Statistical analysis was performed using the Statistical Package for the Social Sciences (SPSS) version 23.0 for Windows. Continuous variables were expressed as mean values with standard error means (SEMs), and the nominal variables were expressed as numbers and percentages. Analyses of the data included testing the differences in prevalence and comparison of the means by using the chi-square test (or Fisher's exact test, where appropriate) and Student's $t$-tests in cases of continuous data. In all cases, a $P$ value less than 0.05 was considered statistically significant.

\section{Results}

A total of 90 patients were enrolled into the study, of which $87(96.7 \%)$ completed the acute treatment phase and 77 subjects $(85.6 \%)$ were followed up during the preventive phase. Three patients from the active group dropped out from the study during the acute treatment phase (diarrhoea after the first dose, nausea, and noncompliance with the study protocol). Ten patients ( 7 in the active group and 3 in the placebo group) decided to withdraw from the study prematurely after the acute treatment phase due to personal reasons and noncompliance with the study protocol. Demographic characteristics are summarized in Table 1.

In the active group, a higher proportion of females [32 $(65.3 \%)$ vs. $21(51.2 \%) ; P=0.176]$ and a higher average age $(25.3 \pm 2.3$ years vs. $17.4 \pm 1.5$ years; $P=0.005)$ were found. No significant differences regarding the number of patients in different stages of herpes infections (prodromal/tingle stage, blister stage, or weeping stage) or the number of herpes exacerbations during the last 6 to 12 months before the study were observed. The patients from the active group had a significantly shorter duration of herpes symptoms leading to their earlier improvement compared to the patients treated with placebo $(11.0 \pm 0.4$ days vs. $12.2 \pm 0.5$ days; $P=0.046$ ) (Figure 1).

The incidence of the side effects was without significant differences between the groups $(P=0.283)$. On days 5 and 6 , we observed a significantly higher number of asymptomatic patients in the active group compared to the placebo group (13\% vs. $0 \% ; P=0.027$ and $16 \%$ vs. $0 \%$; $P=0.013$, respectively) (Figure 2). There were no significant betweengroup differences found in the intensity of all herpes symptoms, in the size of the herpes lesions at baseline $(P=0.441)$, and in the absolute change of herpes size within 10 days of treatment $(P=0.496)$.

In all, $63 \%$ of patients in the active group and $78 \%$ of patients in the placebo group $(P=0.127)$ used some form of antiherpetic concomitant therapy during the acute phase. Despite that the duration of herpes was shorter in the active group. Other therapy, nonrelated to the herpes infections, was used by $13.0 \%$ and $12.2 \%$ of subjects in the active and placebo groups, respectively $(P=0.905)$.

The acute treatment phase was followed by a 120 -day preventive phase (39 patients in the active group and 38 patients in the placebo group) (Table 1). The sex and age distributions remained similar to the preventive phase. No differences in the prevalence of side effects were observed between the groups ( $5.1 \%$ vs. $5.3 \% ; P=1.00$ ). In all, $46.2 \%$ of patients in the active group and $63.2 \%$ of patients in the placebo group $(P=0.134)$ used some form of concomitant therapy (e.g., antibiotics, symptomatic treatment of respiratory infections, and antiherpetic therapy) during the preventive phase. Additionally, we observed a tendency toward lower antibiotic use in the active group (12.8\% vs. $28.9 \% ; P=0.081$ ). Analysing the general incidence of various acute respiratory symptoms (rhinitis, cough, sore throat, earache, and fever) and intercurrent diseases (abdominal pain, aphthous stomatitis, labial herpes, shingles, skin rash, and mycotic infections), no significant differences between the groups were found. However, detailed analysis revealed some protective and preventive effects of the applied therapy. The duration of rhinitis and cough during the preventive phase was significantly shorter in the active group compared to the placebo group $(3.36 \pm 0.76$ days vs. $6.45 \pm 1.36$ days; $P=0.050$ and $2.36 \pm 0.62$ days vs. $5.47 \pm 1.19$ days; $P=0.024$, respectively) (Figure 3 ). The intensity of various symptoms generally tended to decrease during the preventive phase; however, a significant difference was found only in the case of cough $(0.19 \pm 0.05$ days vs. $0.41 \pm 0.09$ days; $P=0.035$ ) (Figure 4 ).

\section{Discussion}

This is the first clinical trial studying the potential treatment and preventive effects of a biologically active polysaccharide, pleuran (insoluble $\beta$-glucan isolated from Pleurotus 
TABLE 1: Demographic characteristics of the study groups.

\begin{tabular}{|c|c|c|c|}
\hline \multirow{2}{*}{ Parameter } & \multicolumn{2}{|c|}{ Group } & \multirow{2}{*}{$P$} \\
\hline & Active & Placebo & \\
\hline Acute treatment phase & \multicolumn{3}{|c|}{90 subjects } \\
\hline Patients $(n)$ & 49 & 41 & n.s. \\
\hline Age (years) & $25.3 \pm 2.3$ & $17.4 \pm 1.5$ & 0.005 \\
\hline Males $(n / \%)$ & $17(34.7)$ & $20(48.8)$ & n.s. \\
\hline Females $(n / \%)$ & $32(65.3)$ & $21(51.2)$ & \\
\hline Number of herpes exacerbations during 6 months before study $(n)$ & $2.7 \pm 0.5$ & $1.7 \pm 0.3$ & n.s. \\
\hline Number of herpes exacerbations during 12 months before study $(n)$ & $4.0 \pm 0.5$ & $3.2 \pm 0.4$ & n.s. \\
\hline Preventive phase & \multicolumn{3}{|c|}{77 subjects } \\
\hline Patients $(n)$ & 39 & 38 & n.s. \\
\hline Age (years) & $26.1 \pm 2.5$ & $17.6 \pm 1.4$ & 0.008 \\
\hline Males $(n / \%)$ & $14(35.9)$ & $18(47.4)$ & n.s. \\
\hline Females $(n / \%)$ & $25(64.1)$ & $20(52.6)$ & \\
\hline
\end{tabular}

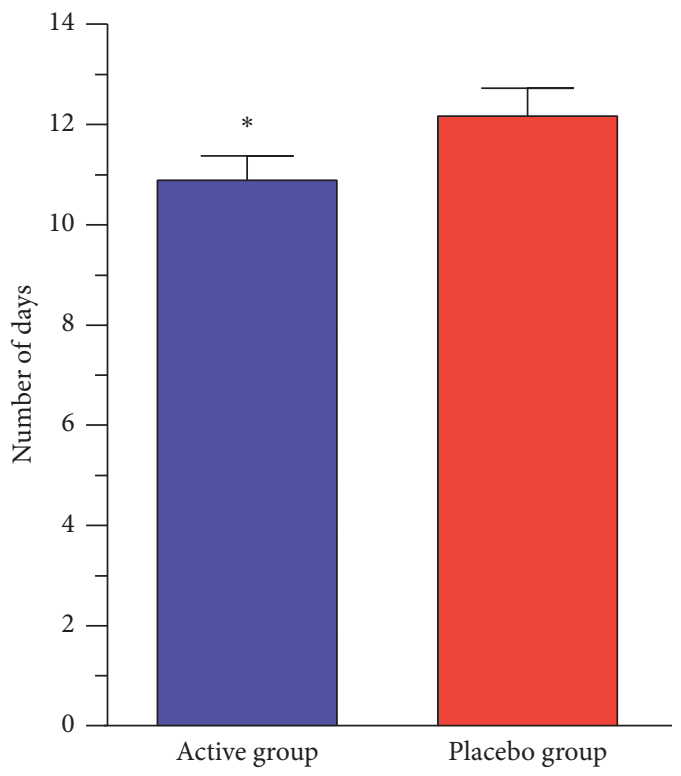

FIgURE 1: Duration of herpes symptoms in active and placebo groups during the acute treatment phase. ${ }^{*}$ Significant difference $(P<0.05)$ in the number of days compared to the placebo group. Data represent mean \pm SEM.

ostreatus), in the management of herpes simplex infections. From 90 patients primarily included in the study, 77 subjects were able to comply with the protocol and finish the study. At the beginning, no differences regarding various characteristics of herpes infection (symptoms and stages of current disease at screening visit and number of labial or facial HSV episodes within the previous 6 to 12 months) were observed between the active and placebo groups. On the other hand, one of the study limitations is related to the different average age in each group (Table 1) which is evident from the fact that the active group included three patients aged over 60 years.

Active treatment with pleuran in systemic application caused shorter duration of herpes simplex symptoms compared to the placebo group. A higher proportion of asymptomatic patients was observed within 5 days in the active group. During the preventive phase, the duration and

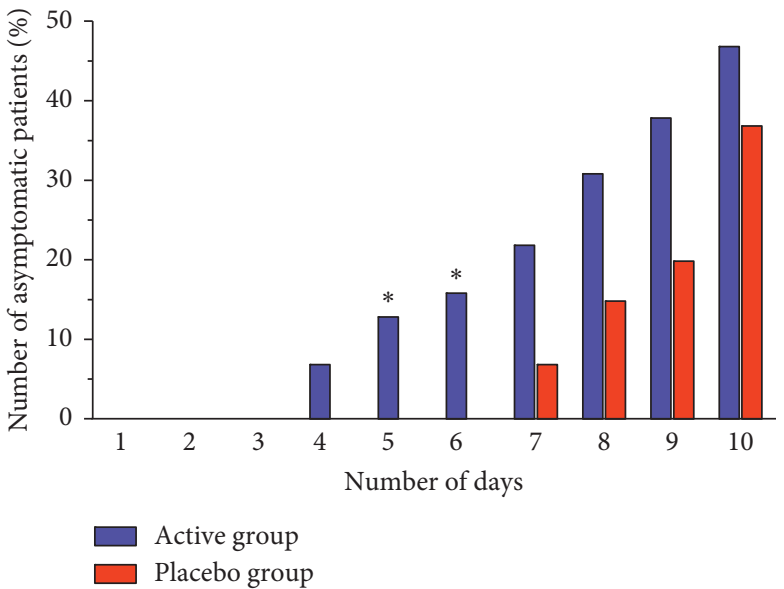

FIgURE 2: Number of asymptomatic patients in active and placebo groups during the acute treatment phase. ${ }^{*}$ Significant difference $(P<0.05)$ in the number of patients compared to the placebo group. Data represent mean values.

severity of respiratory symptoms were lower in the active group compared to the placebo group. No significant side effects were observed during both phases of the clinical trial (acute and preventive).

Infections caused by $\mathrm{HSV}-1$ represent a common problem in childhood as well as in adulthood with variable prevalence. Several studies have shown that the seroprevalence against HSV-1 reaches approximately $40 \%$ by the age of 15 with a subsequent gradual increase to $60-90 \%$ among older adults [29]. Orolabial symptoms caused by HSV-1 are observed in daily clinical praxis more frequently compared to genital herpetic infections. It can occur as a single event, but in certain subjects, it may become recurrent and periodic. The frequency and severity of each episode varies interand intraindividually. For the patients with frequent symptoms of orolabial herpes, it can be associated with painful sensations and social stigmatization with decreased quality of life. It has been shown that orolabial herpes simplex belongs to the most stigmatizing dermatologic diseases [30]. Several factors (e.g., emotional stress, physical effort, respiratory tract infections, mild local trauma, exposure to sun light, and menstruation) have been identified 


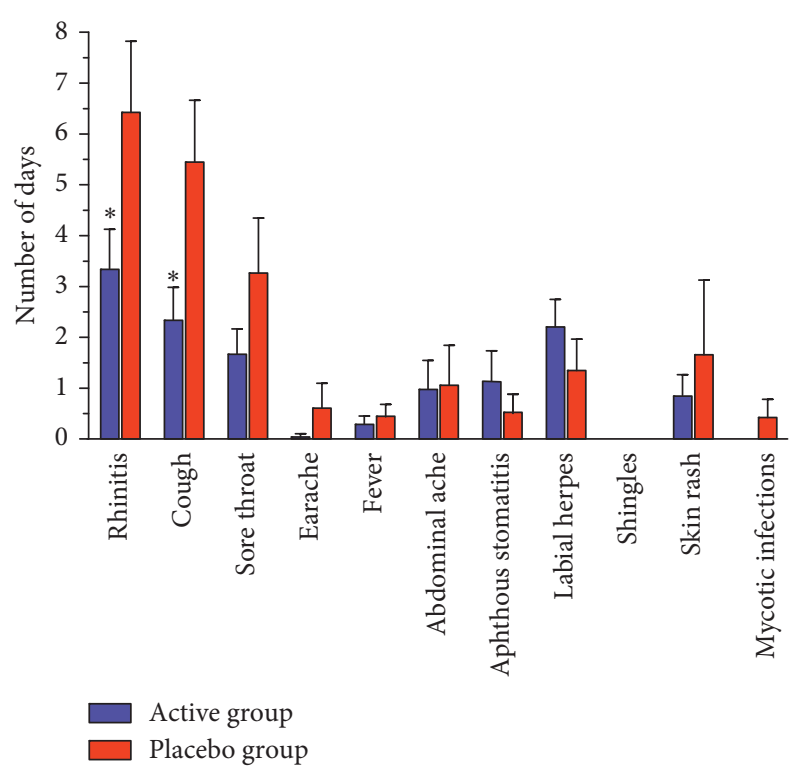

Figure 3: Average duration of the acute respiratory symptoms and intercurrent diseases in active and placebo groups during the preventive phase. * Significant difference $(P<0.05)$ in the number of days compared to the placebo group. Data represent mean \pm SEM.

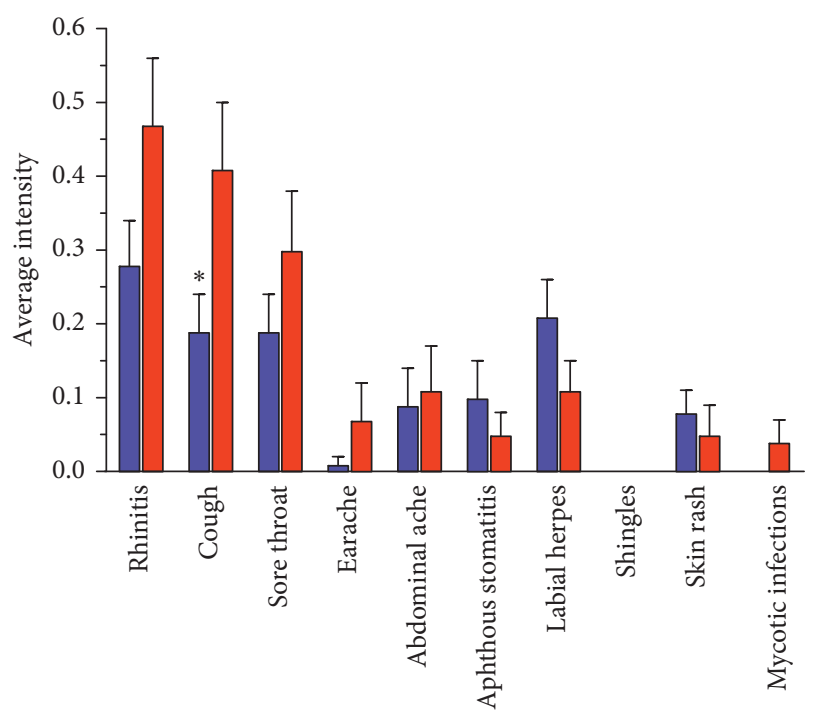

$\square$ Active group
$\square$ Placebo group

FIGURE 4: Intensity of the acute respiratory symptoms and intercurrent diseases in active and placebo groups during the preventive phase. ${ }^{*}$ Significant difference $(P<0.05)$ in average intensity of symptoms compared to the placebo group. Data represent mean \pm SEM.

as possible triggers for recurrent herpetic symptoms. Moreover, immunodepression/immunosuppression can be the underlying cause associated with all of the abovementioned factors [31]. Clinical management should be rational and should be aimed not only on the treatment of acute symptoms but also on the prevention of recurrent symptoms in the future. Treatment strategies should be aimed at the reduction of the ongoing asymptomatic shedding of the virus, which occurs in the oral mucosa about $20-25 \%$ of days of the year [32]. Several antiviral agents were studied in clinical trials (e.g., acyclovir and valacyclovir) in episodic or long-term application. According to the Cochrane Systematic Review, the long-term use of oral antiviral agents can prevent the reoccurrence of labial herpes but the clinical benefit is less [33]. Taking into account the possible undergoing immunodepression, various immunomodulating agents could be another possible option for acute and long-term prophylactic treatment. Several synthetic and natural immunomodulators with possible antiviral activities were studied in the treatment and prevention of labial herpes simplex with various efficacies, including inosine pranobex [34], transfer factors [35-38], topical honey [39], lysine [40], vitamin C [41], and zinc [42].

Biologically active polysaccharides, including $\beta$-glucans, represent one of the most studied group of natural substances with many beneficial biological activities useful in the management and prevention of various pathological conditions of infectious and noninfectious origin. They possess numerous immunomodulatory, anti-infective, antioxidative, and anti-inflammatory properties, which have been described in in vitro murine models as well as human studies [43-45]. Moreover, the revealed mode of action of targeting selected receptors on immune cells put this group of natural substances at the centre of attention of current medicine $[21,22,46]$. However, $\beta$-glucans from various sources could display different biological effects [47]. In our study, we confirmed the positive therapeutic effect of pleuran on the duration and severity of labial HSV-1 infection. To our knowledge, this is the first human study confirming the beneficial effect of $\beta$-glucans in the management of labial herpes symptoms. On the other hand, several in vitro and animal studies have shown the antiHSV-1 efficacy of various $\beta$-glucans and biologically active polysaccharides. In 2011, Santoyo et al. [11] studied the possible antiviral activities of Boletus edulis, P. ostreatus, and Lentinus edodes extracts against HSV-1 in vitro. Their antiviral activity was strong and correlated with the $\beta$-glucan contents presented in the polysaccharide fractions from the natural sources of active substances. Another source of $\beta$-glucans, Ganoderma lucidum, was also studied. Several neutral and acidic protein-bound polysaccharides showed inhibitory activities against both HSV-1 and HSV-2 [48]. Oat $\beta$-glucan feeding in mice resulted in a dose-dependent increase of proinflammatory cytokines (IL- $1 \beta$, IL-6, and TNF- $\alpha$ ) with decreased risk for HSV-1 infection. These cytokines were shown to be important in the physiological immune response and protection against HSV-1 [27]. Oral application of the sulphated derivative of Agaricus brasiliensis mycelial polysaccharide also exhibited anti-HSV-1 activity in a murine model. This natural substance reduced disease scores and accelerated the healing of lesions [49].

Several mechanisms could explain the observed antiHSV - 1 effects from murine models and from the findings in the present study. Among the most important modes of action, the stimulation of cytokine production, activation of NK cells and T lymphocytes, and increased production of 
nitric oxide should be pointed out [50-56]. Another important mechanism could be the activation of DCs, allowing more effective antigen processing and presentation under the condition of HSV-1 infection [57].

During the preventive phase, an additional positive effect on the duration and severity of various respiratory symptoms was also confirmed. The preventive effect of pleuran on respiratory tract infections was confirmed in several openlabel studies in children [58-61]. In a double-blind, placebocontrolled clinical trial, pleuran showed preventive effect with respect to respiratory morbidity and exhibited several modulatory effects on humoral immunity and cellular immunity [62]. Its positive effect on respiratory symptoms and infections was confirmed also in patients with Crohn's disease [63] and elite athletes [64]. In a recent systematic review, we evaluated the effect of various $\beta$-glucans on the treatment and prevention of respiratory tract infections and symptoms [65]. The positive effect of pleuran on respiratory symptoms, their duration, and severity could be explained by its pluripotent biological activities. It supports the production of antibodies, modulates specific cellular immunity, and has positive effect on the activity of NK cells $[62,64]$. It also yielded an anti-infectious effect on selected pathogens [28].

Recurrent labial HSV-1 infections are very common in daily practice and represent one of the most stigmatizing dermatological conditions. The use of various natural substances with revealed mode of action is highly required in current clinical practice. According to our study, the use of pleuran seems to be a promising approach in the treatment of acute labial herpes simplex with an excellent safety profile and beneficial effect on the respiratory tract symptoms and infections, which can be one of the possible triggering factors for labial HSV-1 reoccurrence.

\section{Data Availability}

The data used to support the findings of this study are available from the corresponding author upon request.

\section{Conflicts of Interest}

The authors declare that they have no conflicts of interest.

\section{Acknowledgments}

This study was cofunded by the project Vega, 1/0310/18.

\section{References}

[1] J. A. Bohn and J. N. BeMiller, "( $1 \longrightarrow 3)-\beta$-d-Glucans as biological response modifiers: a review of structure-functional activity relationships," Carbohydrate Polymers, vol. 28, no. 1, pp. 3-14, 1995.

[2] H. A. Pretus, H. E. Ensley, R. B. McNamee, E. L. Jones, I. W. Browder, and D. L. Williams, "Isolation, physicochemical characterization and preclinical efficacy evaluation of soluble scleroglucan," Journal of Pharmacology and Experimental Therapeutics, vol. 257, pp. 500-510, 1991.
[3] D. L. Williams, A. Mueller, and W. Browder, "Glucan-based macrophage stimulators," Clinical Immunotherapeutics, vol. 5, no. 5, pp. 392-399, 1996.

[4] W. Browder, D. Williams, H. Pretus et al., "Beneficial effect of enhanced macrophage function in trauma patient," Annals of Surgery, vol. 211, pp. 605-613, 1990.

[5] E. R. Sherwood, D. L. Williams, and N. R. DiLuzio, "Glucan stimulates production of antitumor cytolitic/cytostatic factor(s) by macrophages," Journal of Biological Response Modifiers, vol. 5, pp. 504-526, 1986.

[6] E. R. Sherwood, D. L. Williams, R. B. McNamee, E. L. Jones, I. W. Browder, and N. R. Di Luzio, "In vitro tumoricidal activity of resting and glucan-activated Kupffer cells," Journal of Leukocyte Biology, vol. 42, no. 1, pp. 69-75, 1987.

[7] J. Majtan and M. Jesenak, " $\beta$-Glucans: multi-functional modulator of wound healing," Molecules, vol. 23, no. 4, p. E806, 2018.

[8] G. Ren, L. Xu, T. Lu, and J. Yin, "Structural characterization and antiviral activity of lentinan from Lentinus edodes mycelia against infectious hematopoietic necrosis virus," International Journal of Biological Macromolecules, vol. 115, pp. 1202-1210, 2018.

[9] M. R. Medina-Gali, M. d. M. Ortega-Villaizan, L. Mercado, B. Novoa, J. Coll, and L. Perez, "Beta-glucan enhances the response to SVCV infection in zebrafish," Developmental \& Comparative Immunology, vol. 84, pp. 307-314, 2018.

[10] Y. Song, W. Zhang, and R. Jaganathan, "Assessment of activity and mechanism of action of $\beta$-D-glucan against dengue virus," Tropical Journal of Pharmaceutical Research, vol. 17, no. 6, pp. 1061-1066, 2018.

[11] S. Santoyo, A. C. Ramírez-Anguiano, L. Aldars-García, G. Reglero, and C. Soler-Rivas, "Antiviral activities of Boletus edulis, Pleurotus ostreatus, and Lentinus edodes extracts and polysaccharide fractions against Herpes simplex virus type 1," Journal of Food and Nutrition Research, vol. 51, pp. 225-235, 2012.

[12] M. Gordon, M. Guralnik, Y. Kaneko, T. Mimura, J. Goodgame, and W. Lang, "Further clinical studies of curdlan sulfate (CRDS)-an anti-HIV agent," Journal of Medicine, vol. 26, pp. 97-131, 1995.

[13] V. Vetvicka and J. Vetvickova, "Glucan supplementation enhances the immune response against an influenza challenge in mice," Annals of Translational Medicine, vol. 3, no. 2, p. 22, 2015.

[14] A. Nakashima, K. Suzuki, Y. Asayama et al., "Oral administration of Euglena gracilis $\mathrm{Z}$ and its carbohydrate storage substance provides survival protection against influenza virus infection in mice," Biochemical and Biophysical Research Communications, vol. 494, no. 1-2, pp. 379-383, 2017.

[15] J. Wang, G. Yu, Y. Li et al., "Inhibitory effects of sulfated lentinan with different degree of sulfation against tobacco mosaic virus (TMV) in tobacco seedlings," Pesticide Biochemistry and Physiology, vol. 122, pp. 38-43, 2015.

[16] M. Gordon, M. Guralnik, Y. Kaneko, T. Mimura, M. Baker, and W. Lang, "A phase I study of curdlan sulfate-an HIV inhibitor. Tolerance, pharmacokinetics and effects on coagulation and on CD4 lymphocytes," Journal of Medicine, vol. 25, pp. 163-180, 1994.

[17] M. Gordon, S. Deeks, C. De Marzo et al., "Curdlan sulfate (CRDS) in a 21-day intravenous tolerance study in human immunodeficiency virus (HIV) and cytomegalovirus (CMV) infected patients: indication of anti-CMV activity with low toxicity," Journal of Medicine, vol. 28, pp. 108-128, 1997.

[18] K. Jung, Y. Ha, S.-K. Ha et al., "Antiviral effect of Saccharomyces cerevisiae beta-glucan to swine influenza virus by 
increased production of interferon-gamma and nitric oxide," Journal of Veterinary Medicine Series B, vol. 51, no. 2, pp. 72-76, 2004.

[19] E. Pietrantoni, F. Signore, G. Berardi, F. Donadio, and C. Donadio, "Role of beta-glucan in the treatment of recurrent candidiasis and HPV-correlated lesions and reparative process of epidermis," Minerva Ginecologica, vol. 62, pp. 1-5, 2010.

[20] G. Adotey, A. Quarcoo, J. C. Holliday, S. Fofie, and B. Saaka, "Effect of immunomodulating and antiviral agent of medicinal mushrooms (immune assist 24/7TM) on CD4+ T-lymphocyte counts of HIV-infected patients," International Journal of Medicinal Mushrooms, vol. 13, no. 2, pp. 109-113, 2011.

[21] R. M. Bloebaum, J. A. Grant, and S. Sur, "Immunomodulation: the future of allergy and asthma treatment," Current Opinion in Allergy and Clinical Immunology, vol. 4, no. 1, pp. 63-67, 2004.

[22] G. D. Brown and S. Gordon, "Immune recognition of fungal $\beta$-glucans," Cellular Microbiology, vol. 7, no. 4, pp. 471-479, 2005.

[23] L. Legentil, F. Paris, C. Ballet et al., "Molecular interactions of $\beta$-(1 $\longrightarrow 3)$-glucans with their receptors," Molecules, vol. 20, no. 6, pp. 9745-9766, 2015.

[24] T. Shigemura, Y. Nakazawa, T. Yoshikawa et al., "Severe acyclovir-resistant herpes simplex virus 1 infection following cord blood transplantation," International Journal of $\mathrm{He}$ matology, vol. 108, no. 3, pp. 237-238, 2018.

[25] F. Cardozo, C. M. Camelini, P. C. Leal et al., "Antiherpetic mechanism of a sulfated derivative of Agaricus brasiliensis fruiting bodies polysaccharide," Intervirology, vol. 57, no. 6 , pp. 375-383, 2014.

[26] M. C. Minari, V. P. Rincão, S. A. Soares, N. M. P. S. Ricardo, C. Nozawa, and R. E. C. Linhares, "Antiviral properties of polysaccharides from Agaricus brasiliensis in the replication of bovine herpesvirus 1," Acta Virologica, vol. 55, pp. 255-259, 2011.

[27] E. A. Murphy, J. M. Davis, A. S. Brown, M. D. Carmichael, A. Ghaffar, and E. P. Mayer, "Effects of oat $\beta$-glucan on the macrophage cytokine response to herpes simplex virus 1 infection in vitro," Journal of Interferon \& Cytokine Research, vol. 32, pp. 362-367, 2012.

[28] S. Karacsonyi and L. Kuniak, "Polysaccharides of Pleurotus ostreatus: isolation and structure of pleuran, an alkali-insoluble $\beta$-D-glucan," Carbohydrate Polymers, vol. 24, pp. 107-111, 1994.

[29] J. S. Smith and N. J. Robinson, "Age-specific prevalence of infection with herpes simplex virus type 2 and 1: a global review," Journal of Infectious Disease, vol. 186, pp. S3-S28, 2002.

[30] J. Donigan, V. Pascoe, and A. Kimball, "Psoriasis and herpes simplex virus are highly stimatizing compared with other common dermatologic conditions: a survey-based study," Journal of the American Academy of Dermatology, vol. 73, pp. 525-526, 2015.

[31] T. Rosen, "Recurrent herpes labialis in adults: new tricks for an old dog," Journal of Drugs in Dermatology, vol. 16, pp. 49-53, 2017.

[32] M. Ramchandani, M. Kong, E. Tronstein et al., "Herpes simplex virus type 1 shedding in tears and nasal and oral mucosa of healthy adults," Sexually Transmitted Diseases, vol. 43, pp. 756-760, 2016.

[33] C. C. Chi, S. H. Wang, F. M. Delamere, F. Wojnarowska, M. C. Peters, and P. P. Kanjirath, "Interventions for prevention of herpes simplex labialis (cold sores on the lips)," Cochrane Database of Systematic Reviews, vol. CD010095, 2015.

[34] Y. You, L. Wang, Y. Li et al., "Multicenter randomized study of inosine pranobex versus acyclovir in the treatment of recurrent herpes labialis and recurrent herpes genital in Chinese patients," Journal of Dermatology, vol. 42, pp. 596-601, 2015.

[35] A. Khan, B. Hanse, N. O. Hill, E. Loeb, A. S. Pardue, and J. M. Hill, "Transfer factor in the treatment of herpes simplex type 1 and 2," Dermatologica, vol. 163, pp. 177-185, 1981.

[36] S. Estrada-Parra, R. Chavez-Ranchez, R. Ondarza-Aquilera et al., "Immunotherapy with transfer factor of recurrent herpe simples type I," Archives of Medical Research, vol. 26, pp. S87-S92, 1995.

[37] J. Bystron, S. Bohac, J. Braunova, and D. Koukalova, "Personal experience with treatment of recurrent herpes infections using combined nonspecific immunostimulation," Casopis Lekaru Ceskych, vol. 131, pp. 137-141, 1992.

[38] J. Bystron, K. Cech, J. Pekarek, and J. Jilkova, "Effect of antiherpes specific transfer factor," Biotherapy, vol. 9, no. 1-3, pp. 73-75, 1996.

[39] N. S. Al-Waili, "Topical honey application vs. acyclovir for the treatment of recurrent herpes simplex lesions," Medical Science Monitor, vol. 10, pp. 94-98, 2004.

[40] R. S. Griffith, A. L. Norins, and C. Kagan, "A multicentered study of lysine therapy in Herpes simplex infection," Dermatologica, vol. 156, pp. 257-267, 1978.

[41] G. T. Terezhalmy, W. K. Bottomley, and G. B. Pelleu, “The use of water-soluble bioflavonoid-ascorbic acid complex in the treatment of recurrent herpes labialis," Oral Surgery Oral Medicine Oral Pathology, vol. 45, pp. 56-62, 1978.

[42] F. Femiano, F. Gombos, and C. Scully, "Recurrent herpes labialis: a pilot study of the efficacy of zinc therapy," Journal of Oral Pathology and Medicine, vol. 34, pp. 423-427, 2005.

[43] V. Vetvicka and J. C. Yvin, "Effects of marine $\beta-1,3$ glucan on immune reactions," International Immunopharmacology, vol. 4, pp. 721-730, 2004.

[44] G. D. Ross, V. Vetvicka, J. Yan, Y. Xia, and J. Vetvickova, "Therapeutic intervention with complement and $\beta$-glucan in cancer," Immunopharmacology, vol. 42, pp. 61-74, 1999.

[45] H. Stier, V. Ebbeskotte, and J. Gruenwald, "Immune-modulatory effects of dietary yeast beta-1,3/1,6-D-glucan," $N u$ trition Journal, vol. 13, no. 38, pp. 1-9, 2014.

[46] J. J. Volman, J. D. Ramakers, and J. Plat, "Dietary modulation of immune function by $\beta$-glucans," Physiology \& Behavior, vol. 94, pp. 276-284, 2008.

[47] V. Vetvicka and J. Vetvickova, "Physiological effects of different types of $\beta$-glucan," Biomedical Papers, vol. 151, pp. 225-231, 2007.

[48] S. K. Eo, Y. S. Kim, C. K. Lee, and S. S. Han, "Antiherpetic activities of various proteins bound polysaccharides isolated from Ganoderma lucidum," Journal of Ethnopharmacology, vol. 68, pp. 175-181, 1999.

[49] F. T. G. S. Cardozo, I. V. Larsen, E. V. Carballo et al., "In vivo anti-herpes simplex virus activity of a sulfated derivative of Agaricus brasiliensis mycelial polysaccharide," Antimicrobial Agents \& Chemotherapy, vol. 57, pp. 2541-2549, 2013.

[50] S. Sipka, I. Boldogh, G. Abel, J. Csongor, J. Fachet, and G. Szegedi, "Effects of herpesvirus infections on the chemiluminescence induced by zymozan phagocytosis in mouse peritoneal macrophages," Acta Microbiologica Academiae Scientiarum Hungaricae, vol. 34, pp. 115-120, 1987.

[51] V. Vetvicka, B. P. Thornton, and G. D. Ross, "Soluble $\beta$-glucan polysaccharide binding to the lectin site of neutrophil or 
natural killer cell complement receptor type 3 (CD11a/CD18) generates a primed state of the receptor capable of mediating cytotoxicity of iC3b-opsonized target cells," Journal of Clinical Investigation, vol. 98, pp. 50-61, 1996.

[52] C. R. Brandt and F. Piraio, "Mushroom antivirals," Recent Research Developments in Antimicrobial Agents \& Chemotherapy, vol. 4, pp. 11-26, 2000.

[53] M. Zhang, P. C. K. Cheung, V. E. C. Ooi, and L. Zhang, "Evaluation of sulfated fungal $\beta$-glucans from the sclerotium of Pleurotus tuber-regium as a potential water-soluble antiviral agent," Carbohydrate Research, vol. 339, pp. 2297-2301, 2004.

[54] K. Hayashi, T. Nakano, M. Hashimoto, K. Kanekiyo, and T. Hayashi, "Defensive effects of fucoidan from brown alga Undaria pinnatifida against herpes simplex virus infection," International Immunopharmacology, vol. 8, pp. 109-116, 2008.

[55] T. Yang, M. Jia, S. Zhou, F. Pan, and Q. Mei, "Antivirus and immune enhancement activities of sulfated polysaccharide from Angelica sinensis," International Journal of Biological Macromolecules, vol. 50, pp. 768-772, 2012.

[56] V. Vetvicka and J. Vetvickova, "Immune-enhancing effects of maitake (Grifola frondosa) and shiitake (Lentinula edodes) extracts," Annals of Translational Medicine, vol. 2, p. 14, 2014.

[57] E. A. Munz, J. M. Davis, and M. D. Carmichael, "Immune modulating effects of beta-glucan," Current Opinion in Clinical Nutrition and Metabolic Care, vol. 13, pp. 656-661, 2010.

[58] M. Jesenak, L. Sanislo, R. Kuniakova, Z. Rennerova, J. Buchanec, and P. Banovcin, "Imunoglukan $\mathrm{P} 4 \mathrm{H}^{\circledR}$ in the prevention of recurrent respiratory infections in childhood," Ceskoslovenska Pediatrie, vol. 73, pp. 639-647, 2010.

[59] J. Sapena Grau, L. Pico Sirvent, M. Morera Ingles, and M. Rivero Urgell, "Beta-glucans from Pleurotus ostreatus for prevention of recurrent respiratory tract infections," Acta Pediatrica Espanola, vol. 73, pp. 186-193, 2015.

[60] J. Pasnik, A. Slemp, A. Cywinska-Bernas, K. Zeman, and M. Jesenak, "Preventive effect of pleuran ( $\beta$-glucan isolated from Pleurotus ostreatus) in children with recurrent respiratory tract infections-Open-label prospective study," Current Pediatric Research, vol. 21, pp. 99-104, 2017.

[61] V. Vetvicka, J. Richter, V. Svozil, L. Rajnohova Dobiasova, and V. Kral, "Placebo-driven clinical trials of transfer point glucan \#300 in children with chronic respiratory problems: III. Clinical finding," American Journal of Immunology, vol. 9, pp. 88-93, 2013.

[62] M. Jesenak, J. Majtan, Z. Rennerova, J. Kyselovic, P. Banovcin, and M. Hrubisko, "Immunomodulatory effect of pleuran ( $\beta$-glucan from Pleurotus ostreatus) in children with recurrent respiratory tract infections," International Immunopharmacology, vol. 15, pp. 395-399, 2013.

[63] M. Batovsky, T. Zamborsky, R. Khaled, B. Desatova, and B. Kadleckova, "Beta-(1,3/1,6)-D-glucan helps to decrease opportunistic infections in Crohn's disease patients treated with biological therapy," Archives of Clinical Gastroenterology, vol. 1, pp. 5-8, 2015.

[64] K. Bergendiova, E. Tibenska, and J. Majtan, "Pleuran ( $\beta$-glucan from Pleurotus ostreatus) supplementation, cellular immune response and respiratory tract infections in athletes," European Journal of Applied Physiology, vol. 111, pp. 20332040, 2011.

[65] M. Jesenak, I. Urbancikova, and P. Banovcin, "Respiratory tract infections and the role of biologically active polysaccharides in their management and prevention," Nutrients, vol. 9, p. E779, 2017. 